\title{
Language Planning and Policy: Negotiating with Global Actors in Local Contexts
}

\section{Dushyanthi Mendis}

Professor in English, Department of English, University of Colombo

\begin{abstract}
Although language is a crucial concern at all levels of education in plurilingual communities, the processes of language planning and policy in institutions of higher education in Sri Lanka have received less attention than at the secondary school level. The objective of this article is to address this gap by examining an intervention by a global actor in English language teaching at the Faculty of Arts, University of Colombo, from the perspectives of goals, outcomes, and underlying ideologies. While it is not always possible to resist top-down policy directives from external actors who wield both financial and institutional power, this article argues that negotiation and navigation are possible, provided that the local actors are prepared to claim agency and power at micro levels of planning and implementation.
\end{abstract}

\section{KEY WORDS:}

Agency and power, language planning, language policy

Suggested Citation: Mendis, D. (2021). Language planning and policy: Negotiating with global actors in local contexts. University of Colombo Review (New Series III), 2(1), 29 - 41.

(C) 2021 The Authors. This work is licenced under a Creative Commons Attribution 4.0 International Licence which permits unrestricted use, distribution, and reproduction in any medium, provided the original work is properly cited. 


\section{Introduction}

Language policies are very much a part of an education system. However, the reason or justification for these policies may not always be clear and may not be a result of stakeholder participation. This article will discuss processes of language planning and

policy design at the Faculty of Arts, University of Colombo, taking, as a focal point, an intervention for the enhancement of English language skills, which was a part of the Improving Relevance and Quality of Undergraduate Education (IRQUE) program funded by the World Bank. Although this program was held for students in the Faculties of Arts, Education, Law, Management and Finance, and the Sri Palee Campus of the University of Colombo, this article discusses features of the English Language Teaching (ELT) component conducted in the Faculty of Arts. The IRQUE program was the first time an external actor had provided substantial funding for the teaching of English in the university system. It was not, however, the last. The World Bank has continued to make interventions in Sri Lanka's higher education sector. In this context, a review of the outcomes of a global actor entering local contexts of ELT, and attempting to influence the teaching of English as a second language within the university system, is justified.

Beginning with a brief introduction to language planning and policy (LPP) and the theoretical approaches to LPP that are particularly relevant to the field of education, this article will review the literature available on LPP in Sri Lanka to emphasize the importance of these processes in plurilingual contexts. These studies, though few in number, shed light on the socio-historical factors that have influenced and impacted language use and attitudes in the education sector. Using the outcomes of the IRQUE program's ELT component, and theories of language-in-education, the article will discuss the implications of external interventions in processes of LPP decisions at the Faculty of Arts, University of Colombo.

\section{Language Planning and Policy}

Language planning is a systematic, organized process usually undertaken or spearheaded by a national government or a government entity such as a Ministry or state institution with a mandate for such activity. It is typically a response to an existing problem or an anticipated problem and its goal is to provide solutions or a resolution to the problem. The literature on language planning abounds with descriptions and definitions of the processes that come under its purview. Over the years, these processes have become more and more complex, given the language problems which planners have been called upon to solve. The following early description by Jernudd (1990) offers a broad definition of the agents, goals, and outcomes of language planning:

Language planning is proactive, organized language management which typically but not necessarily proceeds with government-authorized involvement by public agencies and / or with the support of subsidy. Language planning can be understood as a problemsolving process for the language community. It offers a framework for people to try for the best decisions for the future. In the language planning process, people negotiate what seems to them to be the most satisfactory solution to a set of language problems within their limits of control and cognition. (pp. 52-53) 
Historically, language planning, if viewed as a process of language management, has existed since at least the 16th Century (Nahir, 1984), although Kaplan (2013), pointing to instances of the language of conquerors being imposed on the conquered, observes that language planning, in one way or another, is as old as human civilization. By the 1960s, language planning had come to be seen as an academic discipline and a significant field of research (Baldauf, 2012; Ricento, 2000; Wee, 2011). This was as a result of linguists' efforts in developing writing systems and dictionaries for indigenous languages (Ricento, 2000) - generally understood as processes of corpus planning - and the selection of a language or languages for unification of a region or nation for the purposes of modernization or democratization (Rubin \& Jernudd, 1971), i.e., status planning. In the 21 st century, language planning is recognized as a multidisciplinary and interdisciplinary field that encompasses linguistics, political science, sociology and history (Ricento, 2000). Language planning also plays a significant role in education, because nowhere are the forces of language change more apparent than in spheres of education around the world, under pressures exerted by trends of globalization, internationalization and the spread of neo-liberal ideologies.

Four approaches to language planning highlighted by Baldauf (2012) are particularly relevant to LPP initiatives in education. The classical or traditional approach is primarily goal-oriented in relation to status planning, corpus planning, language-in-education planning etc. The language management approach is sociocultural in nature, and focuses on communicative acts that take place in interactions between individuals, or at the institutional level. Language management is described as "very situation oriented" (Baldauf, 2012, p. 237). The third approach is the domain approach, which looks at language planning in domains such as the family, the workplace, the school, public spaces, etc. The last approach is the critical approach which Tollefson (2006) describes as a critical response to the hegemonic approaches found in classical language planning (cited in Baldauf, 2012, p. 237). In other words, this is an approach which looks at, and questions, inequalities caused by language planning and policies, and highlights issues of power, hegemony, and resistance.

Each of these approaches is relevant to LPP initiatives in education in Sri Lanka. LPP in educational settings cannot, and should not, happen without an identification of goals, which should be linked to outcomes. Language management is important in terms of language rights and social harmony in plurilingual learning environments such as those of Sri Lankan universities. The domain approach is relevant to LPP because the medium of instruction in primary and secondary schools in Sri Lanka tends to be Sinhala or Tamil, but students may well encounter a shift to English medium instruction at the tertiary level. Finally, it goes without saying that, since LPP interventions are rarely apolitical, goals, actors, and processes of LPP should be subject to careful and critical scrutiny.

Language policy is the main outcome of language planning. Smitherman (2000) defines a language policy and its connection to language planning as "[a] language policy is a law, rules or precepts designed to bring about language change. Such a policy is encoded in mechanisms of language planning undertaken by governments, schools and other institutional bodies" (as cited in Fodde, 2002, pp. 13-14). Spolsky (2004) offers a broader 
definition, stating "[1] anguage policy may refer to all the language practices, beliefs and management decisions of a community" (p. 9). Language policies can, therefore, be formal decisions as well as practices (Ricento \& Hornberger, 1996). Schiffman (1996) makes an important point to keep in mind - that language policies can be overt or codified (explicit and formalized), or covert (implicit, informal, or unstated) (p. 13). Needless to say, both overt and covert language policies can, and do, impact the communities in which they operate.

\section{Language Planning and Policies in Higher Education}

Language planning is of particular importance in higher education, because, as Liddicoat (2016) observes, the work of universities is "fundamentally mediated by language" and "[o]f all levels of education, higher education has been the most internationalized" (p. 231). Ali (2013) and Liddicoat (2016) see universities as language planning actors that function at the meso and micro levels at which language is planned, where the meso level is the institution itself and the micro level represents individuals, i.e., groups of academic and/ or administrative staff or students. Above these two levels is the macro or national level. This three-level conceptualization draws on, and from Ricento and Hornberger's metaphor of language planning and policy as an onion of several layers, with each layer representing components such as agents, goals or processes (1996, p. 408). These layers do not exist or operate in isolation, as each one permeates and interacts with the others in various ways:

In terms of LPP processes, at the outer layers of the onion are the broad language policy objectives articulated in legislation or high court rulings at the national level, which may then be operationalized in regulations and guidelines; these guidelines are then interpreted and implemented in institutional settings, which are composed of diverse, situated contexts (e.g., schools, businesses, government offices); in each of these contexts, individuals from diverse backgrounds, experiences, and communities interact. At each layer (national, institutional, interpersonal), characteristic patterns of discourse, reflecting goals, values, and institutional or personal identities, obtain. (Ricento \& Hornberger, 1996, p. 409).

In the context of higher education in Sri Lanka, universities, as institutions positioned at the meso level, have to negotiate with and navigate between policies and directives of the central national government at the macro level, and the needs, beliefs and ideologies that play out among stakeholders at the micro level. This often puts universities and the faculties contained within them in an unenviable position of having to satisfy two entities that could be pulling in ideologically opposite directions with regard to language use, attitudes, and beliefs.

Sri Lanka's macro level language policy as it pertains to higher education is found in Chapter IV, Article 21 of the Constitution of the Democratic Socialist Republic of Sri Lanka. Article 21 states that:

(1) A person shall be entitled to be educated through the medium of either of the National Languages: 
Provided that the provisions of this paragraph shall not apply to an institution of higher education where the medium of instruction is a language other than a National Language.

(2) Where one National Language is a medium of instruction for or in any course, department or faculty of any University directly or indirectly financed by the State, the other National Language shall also be made a medium of instruction for or in such course, department or faculty for students who prior to their admission to such University, were educated through the medium of such other National Language:

Provided that compliance with the preceding provisions of this paragraph shall not be obligatory if such other National Language is the medium of instruction for or in any like course, department or faculty either at any other campus or branch of such University or of any other like University.

(3) In this Article "University" includes any institution of higher education.

Thus, universities and other institutes of higher education, unlike schools, are not limited to offering instruction in Sinhala and Tamil, the two National Languages. The medium of instruction in universities and other higher education institutes (HEIs) can be English - or in fact any language other than one of the National Languages. An important point to bear in mind here is that there is a distinction between teaching an academic discipline in English (English as a medium of instruction or EMI) and the teaching of English as a second language (ESL). In Faculties of Arts, where students' English proficiency levels tend to be low, LPP interventions encompass both these functions of English. The focus of this article, however, is on an ESL program.

In Sri Lanka there has been a tendency for language planning and policy mechanisms in higher education to be overshadowed by an emphasis on the planning and execution of more traditional academic disciplines and programs of study. While committees are appointed by universities and faculties for the design and review of mainstream curricula, few or no committees are appointed for the specific purpose of language planning and policy, even though language policy has been a thorny issue in Sri Lanka's post-independence era for many areas (Coperahewa, 2009; Irshad, 2018; Medawattegedera, 2015; Perera, 2015; Raheem, 2006; Raheem \& Ratwatte, 2004; Vamadevan, 1996). If such committees are appointed, there is no guarantee that they will be led by linguists, who, being trained in theoretical and applied disciplines of language and language use, are arguably the best equipped to make informed recommendations and decisions about language policies in plurilingual contexts. As Ricento and Hornberger observe, "the practitioner is often an afterthought who implements what experts in the government, board of education or central school administration have already decided" (1996, p. 417). This has unfortunately often been the case in Sri Lankan universities as well, as will be discussed later in this article.

Few universities in Sri Lanka have explicitly stated policies with regard to institutional language use, except for information about the medium of instruction used in individual faculties, which is available in the University Grants Commission's “Admissions Handbook" for students (2019/2020). A lack of information on language policies is not 
unique to HEIs in Sri Lanka. Commenting on the university system in Malaysia, Ali observes that while the use of English medium instruction "is central to a range of policy goals, the policy statements on the use of English as medium of instruction [sic] have been hidden behind the broader policy goals for higher education institutions" (2013, p. 81).

Another problem in the Sri Lankan university system is that language policies often function in an ad hoc manner, i.e., as unstated or implicit institutional practices rather than as "an officially mandated set of rules for language use and form" (Spolsky, 2012, p. 3). The problem with this type of situation is that, as Ali (2013) correctly observes, directives about language use that are verbally transmitted do not promote consistent policy development. Further, in terms of national unification and social cohesion, there is a danger in language policies operating in an ad hoc manner in the education sector, especially in plurilingual countries like Sri Lanka, where language policies have been associated with civil conflict situations in the past (Coperahewa, 2009; Herath, 2015; Mendis, 2001/2002; Raheem and Ratwatte 2004).

Along with a lack of clear-cut policies, there is a corresponding paucity of recent research and inquiry into LPP in Sri Lanka's higher education sector. Most articles which focus on LPP at the tertiary level were published between 2000 and 2010. These early studies are, however, useful for tracing the historical, political, social, and ideological factors that impinged upon, and continue to shape language attitudes, language use, and students' linguistic performance in HEIs even today.

Raheem and Ratwatte (2004) trace the historical trajectory of LPP initiatives from Sri Lanka's post-independence era onwards, with a focus on the role and status of English in the country. They argue that to understand the true picture, one needs to also understand the linguistic processes, history, and acculturation of English in Sri Lanka. As a part of this history, they point to the effects of the "Sinhala Only" policy of 1956, which resulted in the removal of English as a medium of instruction from schools. This policy, brought into effect by the Official Language Act No 33 of 1956, also led to the discontinuation of special teacher training colleges set up to train English teachers, because the need for English teachers began to decrease (Raheem \& Ratwatte, 2004). More significantly, and of particular relevance to the present article, Raheem and Ratwatte observe that Sri Lanka found itself in a quandary, as it had to find a way to retain English as a medium of communication at a global level (2004, p. 96). This is an early example of how global and international forces influence local language policy decisions.

Raheem and Ratwatte claim that, in the field of higher education, the nationalist language policy which dictated the use of either Sinhala or Tamil as a medium of instruction, "was quite openly ignored" (2004, p. 96) in the 1960s and 1970s. They note that Faculties of Medicine, Science, and Engineering continued to teach in English, but they make no mention of English medium instruction in Faculties of Arts and Humanities. However, given that in Faculties of Arts, Humanities, and Social Sciences, significant amounts of teaching are done in Sinhala and Tamil today, it can be assumed that these Faculties did make the shift to the National Languages as media of instruction. A final point Raheem and Ratwatte make is that "invisible" or unplanned forces can influence the implementation of language 
planning and policy. The "invisible forces" they refer to are ethnic tensions, global trade patterns and labor market forces etc. More than fifteen years later, some of these "invisible forces" - especially those related to the labor market and graduate employability - have become very visible and have even entered the discourse on LPP decisions in universities.

Two studies on language attitudes conducted in two different universities adopt a bottom-up approach in identifying stakeholder needs and opinions on language use. Mendis (2001/2002) investigated language attitudes in a sample of 63 randomly selected first year undergraduate students at the Faculty of Arts, University of Colombo, during the period of their Intensive English course - i.e., before beginning their academic courses of study at the university. The rationale for selecting first year students was that, since they had recently transitioned from the secondary school system to the tertiary level, they would be an ideal population for researching attitudes, ideologies and linguistic consciousness at both these levels of education (Mendis 2001/2002, p. 168). A majority of the participants (63.5\%) had responded that three languages - English, Sinhala, and Tamil - should be taught in schools. One could consider these views as a precursor to the Trilingual Nation initiative which the government of Sri Lanka introduced in 2012. None mentioned the use of English as a link language. From their qualitative responses it was clear that "English... [was] regarded principally as a language of higher education and professional advancement" (p.180).

In the second study, Raheem (2006) investigated attitudes towards language/s in a different university population, i.e., staff in academic and administrative positions at the Open University of Sri Lanka (OUSL). These staff members were specially selected for their leadership positions (Deans of Faculties, Heads of Departments), whose opinions and ideologies could make an impact on the institution's language policy/ies. The particular relevance of Raheem's study to the current article is the observation she makes about a far too common issue in language planning: that decisions about languages are made more often by "administrative fiat" than by popular will (p. 13). Raheem also observes that determining the role of English in multilingual settings is more often a result of "global imperatives" (p. 13) rather than purely local needs. Raheem also points to the danger inherent in topdown practices in language planning because they can exacerbate relations of power and inequality. Supporting a bottom-up approach to language policy interventions, Raheem asserts that:

Determination of a policy requires a great deal of information - on the languages, who uses them, for what purpose or purposes, the resources needed to expand or develop the languages, the links between the languages and the educational system etc. - but rarely are such questions asked. (p. 14)

Raheem and Ratwatte (2001) question the practicality of the notion of standardization of competence in LPP. This notion assumes that all students or learners should demonstrate a similar level of competence at the end of an ELT course, irrespective of other factors that impinge upon language learning (p. 23). Raheem and Ratwatte's analysis of the variability of scores from an English test conducted by the OUSL across all nine provinces of Sri Lanka led them to conclude that "Sri Lanka's national language policy has resulted not in a uniform standard of competence but in variations across the country" (p. 35). They also 
observed, in this same study, that "[o]fficial policy which in the 1960s and 1970s centered on discouraging English has now done a turnabout and trumpets the use of English often as the panacea for all problems pertaining to higher education and employment" (p. 29). This is especially true in the discourse on graduate employability related to Faculties of Arts, Humanities, and Social Sciences in Sri Lanka's higher education sector.

Perera's (2006) study draws attention to a micro level of language planning - i.e., designing syllabuses and administering remedial ESL courses. Recognizing that students are the principal stakeholders in LPP interventions in educational settings, Perera asserts that any changes to language planning "must take into account their effect on the student body" (p. 46). Perera gives an account of how student performance (i.e., grades) on an entry-level Placement Test was used to make changes to the content, assessment practices, and timetable hours of an ESL course for first year students at the University of Kelaniya.

\section{Interventions in Language Planning and Policy: The IRQUE Program}

The IRQUE program was, in several ways, the first of its kind at the University of Colombo, and perhaps in Sri Lanka's entire higher education system. It was introduced to universities in 2004, by the University Grants Commission and the Ministry of Tertiary Education and Training (Ilangakoon, 2008). Funding from the World Bank for improving the quality of undergraduate education was offered to universities in the form of competitive institutional block grants (IBGs). The funding was not limited to language teaching. However, an IBG for the enhancement of English language skills targeting final year undergraduates of the Faculties of Arts, Education, Law, Management and Finance, and the Sri Palee Campus of the University of Colombo constituted a significant project.

The most significant feature of the IRQUE program operationalized through the IBG was a complete lack of consultation with the local actors responsible for implementing the interventions related to English language teaching within the university. As Ilangakoon (2008) notes, the goals, learning outcomes, course content and even the number of teaching hours per day were specified by the UGC Task Force on Skills Enhancement in English.

The general and specific aims of the program were as follows: ${ }^{1}$

General Aims:

- To enable students to gain proficiency in grammatical English and use the language with confidence in a variety of situations

- To provide students with the skills necessary for employability

Specific Aims:

- To provide students with Language Knowledge, Grammar, Vocabulary and pronunciation

- To develop their Oral skills as well as Graphic skills

- To develop Soft/social skills through various activities

Woven into the common, familiar objectives of most, if not all, ELT programs are the "real" goals of the IRQUE intervention - i.e., to increase graduate employability through training in soft skills required in the workplace. This was clear in the description of the course content: 
In addressing each of the skills (Listening, Speaking, Reading and Writing) special attention will be paid to providing students with content related to the use of English in the Contemporary Workplace. ${ }^{2}$

Evidence that these goals originated from an external actor - the World Bank - can be found in a report available on the World Bank's website (The World Bank, 2003). This report identified several issues in Sri Lanka's tertiary education sector, of which the two most relevant to my focus were that " $[\mathrm{t}]$ eaching and learning practices do not encourage the acquisition of competencies and social skills demanded in the labor market" and that "[1] ow quality and poor economic and social relevance of the educational programs offered by the public universities contribute to high graduate unemployment" (The World Bank, 2003 , p. 2). The neo-liberalism which underpinned the IRQUE program was quite apparent here. From such a perspective, universities are viewed as (factory) sites in which human resources - i.e., employable graduates - are molded for the labor market (Jayawardena, 2017 , p. 223). The overt infiltration of this ideology into Sri Lanka's higher education sector can be traced to this IRQUE program, which did not attempt to conceal its intended outcomes.

This was evident in how the ELT intervention, dictated by the IRQUE program, played out in the Faculty of Arts. Usually, before the commencement of a new ELT program, a needs analysis is conducted to determine which skills and competencies the target population needs the most. In this case however, this was not done as the skills and competencies had already been determined by the UGC's Task Force on Skills Enhancement in English. In fact, even the textbook to be used for teaching grammar was prescribed by the Task Force (Ilangakoon, 2008).

The first resistance displayed by the staff of the English Language Teaching Unit $(\text { ELTU })^{3}$ towards the IRQUE program concerned this textbook, ${ }^{4}$ which was felt to be too elementary for final year students who would have already had at least one year (if not more) of ESL instruction at the university. Two other textbooks were, therefore, selected after consultation with ELTU staff, which were purchased with the IBG funds. In addition, a team of ELTU staff members designed additional modules titled "Office Talk", "Exchanging Information", "People around Us" and "Selecting a Career" (Ilangakoon, 2008). These ELT materials were tailor-made for the target group and were aimed at filling gaps in the University's on-going English Language Proficiency courses (Ilangakoon, 2008, p. 102). For example, job advertisements from local newspapers were discussed with students to raise awareness of the skills that employers desire and look for in a prospective candidate, and in the speech modules, students were trained in interview and presentation skills such as the use of correct body language and voice projection in addition to the use of appropriate language (Ilangakoon, 2008, p. 102). This was an example of negotiation and navigation on the part of local actors at the micro level when faced with a top-down imposition by a powerful external actor which not only wielded financial power but also institutional power because the UGC and the Ministry of Tertiary Education and Training were intermediaries of the program. The negotiation (selecting appropriate textbook/s) was possible only as a result of a process of mediation with the Director of the Local Technical 
Secretariat, the administrative unit that was set up to assist with the implementation of the IRQUE program. It was fortunate that the Director, a senior member of the university's academic staff, recognized and accepted the expertise and recommendations of the staff of the university's ELTU, thus conferring agency upon practitioners of a LPP intervention.

The outcomes of the IRQUE program were mixed. Citing participant feedback, Ilangakoon (2008) reports that, overall, students were satisfied with the program. Not surprisingly, ratings of "[v]ery useful" were higher for lesson materials designed in-house by the ELTU than for the textbooks used in the program. ${ }^{5}$ Although the student feedback was largely positive, Ilangakoon (2008) cites low student participation - i.e., only 126 students had registered for the program. This number reflects student participation from a single faculty, during one year of a program that provided funds for a three-year period. However, it is still a small number of students for whom the ELTU staff invested many hours in lesson material preparation, and an extra six hours of teaching per day for the duration of the English skills course. A positive outcome, however, was the ELT materials and equipment that the University of Colombo was able to procure through the IBG. According to Ilangakoon (2008):

This course gave us the opportunity to shop for ELT equipment we had always dreamed of having, but were unable to get due to a lack of university funds. With the World Bank funding, we were able to order books, audio cassette players, flip charts, white boards, a TV and a DVD player for the Faculty of Arts. (p. 105)

In this simple but powerful statement, Ilangakoon illustrates the difficult situation of ELT practitioners, caught between a state university system that is supported less each year by the central government, and funding offered by external sources, albeit with global ideological agendas, to increase the effectiveness of their teaching and enhance the learning experience of their students.

\section{Future Directions}

What can be learnt from a retrospective review of the outcomes of the IRQUE program that can help ELT practitioners to negotiate and navigate issues related to LPP in the future when facing an external actor or actors? The injection of funds into HEIs by entities such as the World Bank in the form of loans to the government of Sri Lanka will continue, with universities having little or no possibility of resistance. We should, therefore, equip ourselves to utilize these funds to maximize the benefit to students and academic staff. One of the principal strengths we have as academic members of staff is our position within our respective institutions - we know our students' needs best, and we understand the unique socio-cultural environment of our departments and faculties. This is knowledge we can, and should, use to negotiate from a position of strength, signifying local power and agency. To do so however, we also need information - i.e., data - to support our positions and arguments. Unfortunately, a lack of such data (at least in the Faculty of Arts, University of Colombo) placed us in a position of weakness in the past. For the future, we need to conduct comprehensive needs analyses and surveys, which should not only 
be focused on syllabus specifications derived from target-situation needs, but also include practicalities and constraints, teaching methods, and learning strategies, as well as materials selection (West, 1994, p. 1). The two published studies cited in this article, those of Mendis (2001/2002) and Ilangakoon (2008), surveyed small student populations. Mendis surveyed 63 students, and Ilangakoon, although starting off with a cohort of 126 students, was able to obtain feedback from only 63 at the end of the program. In a faculty of approximately 2500 students, these samples are not adequate to counter negative statements such as those voiced in the World Bank Report of 2003, which are then used to justify external LPP and other interventions in HEIs.

Finally, surveying target populations, which should include not only students but academic and administrative staff as well, is of vital importance in language planning to ensure a participatory approach in the designing of policies. Ricento and Hornberger (1996) make this very clear when they recommend "a participatory approach that centers on students' rather than society's needs" (p. 421) and place the classroom practitioner at the heart of language policy (p. 417). Ensuring maximum participation in language planning is especially crucial in the case of policies related to ELT, given the complex nature of the attitudes and ideologies related to English in Sri Lanka. More than 60 years after the expulsion of English as a medium of education, the presence of English in the curriculum can still cause conflict, as Medawattegedera's (2015) account of the results of a recent language policy intervention in Sri Lanka's secondary school system makes clear. It is best therefore, to question, scrutinize, and carefully evaluate LPP not only in one specific Faculty of Arts, but in the university system as a whole, in order to avoid situations of dissatisfaction and even conflict.

1. (Personal communication, Local Technical Secretariat, n.d.)

2. (Personal Communication, Local Technical Secretariat, n.d.)

3. The ELTUs are now known as DELTs (Department of English Language Teaching)

4. Wijesinha, R. (2004). A handbook of English grammar. Cambridge University Press in India Private Limited.

5. Two of the three textbooks used in the program were authored by non-Sri Lankans and contained material that was not always familiar or relatable to the students. These textbooks, both published by Cambridge University Press, were selected because the IRQUE program mandated the teaching of Business English and the development of vocabulary skills, and no appropriate textbooks published locally in Sri Lanka could be found for this purpose.

\section{References}

Ali, N. L. (2013). A changing paradigm in language planning: English-medium instruction policy at the tertiary level in Malaysia. Current Issues in Language Planning, 14(1), 73-92.

Baldauf, R. B. (2012). Language planning: Where have we been? Where might we be going?" RBLA, Belo Horizonte, 12(2), 233-248. 
Constitution of the Democratic Socialist Republic of Sri Lanka, Chapter IV, Article 21.

Coperahewa, S. (2009). The language planning situation in Sri Lanka. Current Issues in Language Planning, 10(1), pp. 69-150.

Fodde, L. (2002). Race, ethnicity and dialects: Language policy and ethnic minorities in the United States. FrancoAngeli.

Herath, S. (2015). Language policy, ethnic tensions and linguistic rights in post war Sri Lanka. Language Policy, 14, pp. 245-261.

Ilangakoon, S. (2008). Designing a tailor-made course for IRQUE at the University of Colombo. In D. Fernando \& D. Mendis (Eds.), English for equality, employment and empowerment (pp.99106). Sri Lanka English Language Teachers' Association.

Irshad, M. (2018). Trilingualism, national integration and social coexistence in postwar Sri Lanka. In I. Liyanage (Ed.), Multilingual Yearbook 2018 (pp. 107-124). Springer.

Jayawardena, D. (2017). The "Macburger", non-state universities and the changing landscape of higher education in Sri Lanka. Journal for Critical Education Policy Studies, 15(3), 213-240.

Jernudd, B. H. (1990). Two approaches to language planning. In V. Bickley (Ed.), Language use, language teaching and the curriculum (pp. 48-53). Institute of Language in Education.

Kaplan, R. B. (2013). Language planning. Applied Research on English Language, 2(1), 1-12.

Liddicoat, A. J. (2016). Language planning in universities: Teaching, research and administration. Current Issues in Language Planning, 16(3-4), 231-241.

Medawattegedera, V. V. (2015). Kaduwa or manne? Issues and tensions related to bilingual education policy in Sri Lanka. OUSL Journal, 8, 39-50.

Mendis, D. (2001/2002). Language planning and ethnicity: Attitudes and perceptions from the education sector. Sri Lanka Journal of the Humanities, 27\&28(1\&2). 161-184.

Nahir, M. (1984). Language planning goals: A classification. Language Problems and Language Planning, 8(3), 294-327.

Perera, K. (2006). Laying the foundations: Language planning in the ELTU. In H. Ratwatte \& S. Herath (Eds.), English in the multilingual environment (pp. 47-57). Sri Lanka English Language Teachers' Association.

Perera, M. (2015). Building bridges: National integration through the teaching of the Second National Language. In H. Coleman (Ed), Language and social cohesion in the developing world (pp.155165). British Council and GTZ Gmbh.

Raheem, R. (2006). Configuring the mosaic: Investigating language use and attitude in Sri Lanka. In H. Ratwatte \& S. Herath (Eds.), English in the multilingual environment (pp. 13-27). Sri Lanka English Language Teachers' Association. 
Raheem, R., \& Ratwatte, H. (2001). Regional variation in student proficiency and its implications for language planning. In D. Hayes (Ed.), Teaching English: Possibilities and opportunities (pp. 23-36). Sri Lanka English Language Teachers’ Association.

Raheem, R., \& Ratwatte, H. (2004). Invisible strategies, visible results: Investigating language policy in Sri Lanka. In S. Mansoor, S. Meraj \& A. Tahir (Eds.), Language policy planning \& practice (pp. 91-105). Oxford University Press.

Ricento, T. (2000). Historical and theoretical perspectives in language policy and planning. Journal of Sociolinguistics, 4(2), 196-213.

Ricento, T. K. \& Hornberger, N. H. (1996). Unpeeling the onion: Language planning and policy and the ELT profession. TESOL Quarterly, 30(3), 401-427. https://doi.org/10.2307/3587691

Rubin, J. \& Jernudd, B. (1971). A view towards the future. In Joan Rubin \& Bjorn Jernudd (Eds.), Can language Be planned? Sociolinguistic theory and practice for developing nations (pp. xiiixxiv). The University Press of Hawaii.

Schiffman, H. F. (1996). Linguistic culture and language policy. Routledge.

Spolsky, B. (2004). Language policy. Cambridge University Press.

Spolsky, B. (2012). What is language policy? In B. Spolsky, (Ed.), The Cambridge handbook of language policy (pp. 3-15). Cambridge University Press.

The World Bank. (2003) Sri Lanka - Improving Relevance and Quality of Undergraduate Education Project (English).

http://documents.worldbank.org/curated/en/119451468777942597/Sri-Lanka-ImprovingRelevance-and-Quality-of-Undergraduate-Education-Project

University Grants Commission. (Academic Year 2019/2020). Admissions to undergraduate courses of the universities in Sri Lanka.

https://www.ugc.ac.lk/downloads/admissions/Handbook_2019_20/ENGLISH\%20 HANDBOOK.pdf

Vamadevan, V. (1996). Tamil in public administration. In K. N. O.Dharmadasa (Ed.), National language policy in Sri Lanka 1956 to 1996 (pp. 113-135). International Center for Ethnic Studies.

Wee, L. (2011). Language policy and planning. In J. Simpson (Ed.), The Routledge handbook of applied linguistics (pp. 11-23). Taylor and Francis.

West, R. (1994). Needs analysis in language teaching. Language Teaching, 27(1), pp 1-19. https://doi.org/10.1017/S0261444800007527

Wijesinha, R. (2004). A handbook of English grammar. Cambridge University Press in India Private Limited. 